\title{
Measles outbreak on a cruise ship in the western Mediterranean, February 2014, preliminary report
}

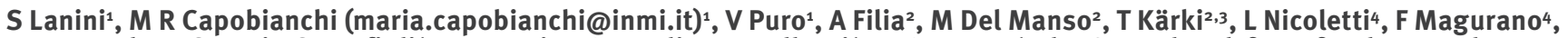
T Derrough ${ }^{5}$, E Severi ${ }^{5}$, S Bonfigli ${ }^{6}$, F N Lauria ${ }^{1}, \mathrm{G}$ Ippolito $^{1}$, L Vellucci ${ }^{6}$, M G Pompa $^{6}$, the Central task force for the measles outbreak ${ }^{7}$

1. National Institute for Infectious Diseases (INMI) “Lazzaro Spallanzani” Rome, Italy

2. Istituto Superiore di Sanità (ISS), National Centre for Epidemiology Surveillance and Health Promotion, Rome, Italy (CNESPS)

3. European Programme for Intervention Epidemiology Training (EPIET), European Centre for Disease Prevention and Control (ECDC), Stockholm, Sweden

4. Istituto Superiore di Sanità (ISS), Department of Infectious, Parasitic and Immune-mediated Diseases, Rome, Italy

5. European Centre for Disease Prevention and Control (ECDC), Stockholm, Sweden

6. Ministry of Health, Directorate General for Prevention, Rome, Italy

7. The members of the Central Task Force for the measles outbreak are listed at the end of the article

Citation style for this article:

Lanini S, Capobianchi MR, Puro V, Filia A, Del Manso M, Kärki T, Nicoletti L, Magurano F, Derrough T, Severi E, Bonfigli S, Lauria FN, Ippolito G, Vellucci L, Pompa MG, the Central task force for the measles outbreak. Measles outbreak on a cruise ship in the western Mediterranean, February 2014 , preliminary report. Euro Surveill. 2014;19(10):pii=20735. Available online: http://www.eurosurveillance.org/ViewArticle.aspx?Articleld=20735

A measles outbreak occurred in February 2014 on a ship cruising the western Mediterranean Sea. Overall 27 cases were reported: 21 crew members, four passengers. For two cases the status crew or passenger was unknown. Genotype B3 was identified. Because of different nationalities of cases and persons on board, the event qualified as a cross-border health threat. The Italian Ministry of Health coordinated rapid response. Alerts were posted through the Early Warning and Response System.

\section{The event}

On 26 February 2014, a cruise line company informed the Unit for the Coordination of the Port, Airport and Border Health Offices (USMAF) of the Italian Ministry of Health $(\mathrm{MoH})$ in Rome of a suspected measles outbreak among crew members aboard one of its ships cruising in the western Mediterranean Sea. The ship's medical staff requested assistance from the USMAF Unit of Civitavecchia, Maritime Health Office and on 27 February, when the ship arrived in Civitaveccia, USMAF staff conducted a thorough assessment of the medical situation on board. Consultants from the National Institute of Infectious Diseases (INMI) 'Lazzaro Spallanzani' undertook a physical examination of patients and the clinical presentation suggested measles. On the same day, the $\mathrm{MoH}$ received the notification of a laboratory-confirmed measles case in a 27-year-old female crew member, who had disembarked the same cruise ship in Genoa, Italy, on 22 February 2014, where she had been hospitalised because of respiratory symptoms, fever and rash.

The cruise ship in question regularly sails on sevenday cruises in the western Mediterranean with ports of call in Italy (Civitavecchia, La Spezia, Savona), France
(Marseille) and Spain (Barcelona, Palma de Mallorca). It has a capacity of up to 3,750 passengers and about 1,000 crew members. Passengers and crew come from a wide range of countries and may embark and disembark at any of the ports listed above. The event thus qualified as a cross-border health threat [1].

After being informed of the outbreak, the $\mathrm{MoH}$ immediately alerted all regional health authorities in Italy by email to ensure timely reporting of measles cases, to request that information about recent travel on the involved cruise ship be collected from all reported cases and that biological samples be sent for genotyping to the national reference laboratory at the Istituto Superiore di Sanità (ISS) in Rome.

Here we report available epidemiological information about the outbreak as of 11 March 2014.

\section{Epidemiological investigations}

In the outbreak investigation we used a case definition based on the European Union (EU) 2012 case definition [2] for classification of measles cases: clinical criteria were restricted to fever and rash and an epidemiologic link was defined as having been aboard the cruise ship after 1 January 2014 or having been in contact with a case linked to the cruise ship outbreak. A probable case was defined as any person meeting the clinical criteria and having an epidemiologic link. A confirmed case was defined as any probable case with laboratory evidence of infection i.e. identification of viral RNA through polymerase chain reaction (PCR) and/or positive IgM serology test.

Information on cases was obtained from the national Italian integrated measles and rubella surveillance 
system whereby physicians are required to report all suspected measles cases to the local health authorities within 12 hours. For each case, local health authorities carry out an epidemiological investigation and obtain specimens for laboratory confirmation. A standard measles notification form is sent to the regional health authorities within 24 hours of being informed by the physician. The regional health authorities, in turn, enter case-based data within 24 hours of receiving a report, into an electronic system developed by the Infectious Diseases Epidemiology Unit of the ISS. In some regions, local health authorities enter data directly into the web-based system [3].

We prepared a line list of cases with information on the presence of symptoms and complications, date of rash onset, hospitalisation, date of embarkation and disembarkation and vaccination status against measles. In addition, information on demographic characteristics, including nationality, of crew members and passengers on board the cruise ship during the week of 22 to 27 February 2014, was obtained from the cruise line company. Acute phase sera were collected from all cases and measles-specific IgG and IgM titers were measured at INMI Spallanzani. Viral detection and genotyping was performed on urine samples by the INMI Spallanzani and by the national reference laboratory using previously described methods $[4,5]$.

\section{Findings}

Overall, 27 measles cases were identified: 24 through the Italian surveillance system ( 21 crew members, four passengers, two cases not specified whether crew or passenger); two cases were reported directly to the Italian $\mathrm{MoH}$ (both passengers) and one case (a passenger) was reported by the Austrian Ministry of Health via the EU's Early Warning and Response System (EWRS). Twenty-two of 27 cases were laboratory-confirmed, the remaining five were classified as probable cases. The age of cases ranged from one year to 42 years (median: 26 years); 21 were men. Information of the country of origin was available for 19 of 27 cases: Italy (6), India (5), Philippines (3), Honduras (2), Austria (1), Brazil (1), and Indonesia (1).

The vaccination status of the 24 cases reported through the Italian Surveillance system reported cases was as follows: unknown vaccination status $(n=12)$, unvaccinated $(n=9)$, vaccinated with 1 or 2 doses $(n=2$, $n=1$ respectively).

The earliest date of onset of rash was on 20 February and the most recent case developed rash on 1 March 2014. Figure 1 shows the distribution of cases by date of rash onset, among crew members and passengers.

On 27 February, 968 crew members aged 26-36 years (median: 30) were on board, 153 (16\%) were women. They originated from four continents: the majority were from Asia (688; 71\%) and Europe (206; 21\%), 68 (7\%) came from South America and the Caribbean and 5
FIGURE 1

Distribution of cases by date of rash onset ${ }^{\mathrm{a}}$ among crew members and passengers, measles outbreak on cruiseship, Italy, as of 11 March $2014(\mathrm{n}=25)$

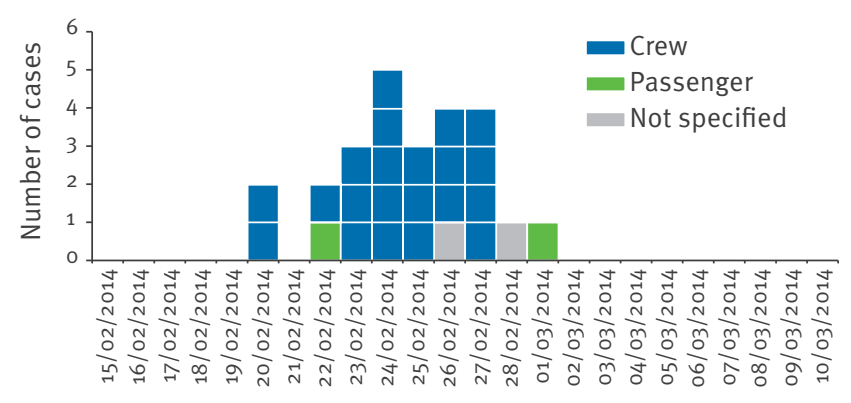

For further two reported cases the date of onset of rash or fever was missing.

$(0,5 \%)$ from Africa. The median stay on board was 248 days (range 228 to 260 days).

During the week of 22 to 27 February 2014 , there were 3,352 passengers on board, of whom 2,891 (86\%) were EU nationals. Over $60 \%$ of EU passengers were of either French or Italian nationals (1,101 and 939 respectively, $38 \%$ and $33 \%$ ). Besides these, the six most frequently represented EU nationalities on board were German (279;10\%), British (124; 4\%), Austrian (113; 4\%) and Spanish $(105 ; 4 \%)$ passengers. The median age of passengers was 41 years (range 6 months to 93 years).

\section{Microbiological results}

Samples for genotyping were collected from 22 cases and measles genotype B3 was identified in samples from 10 cases. Phylogenetic analysis demonstrated that identified sequences were $100 \%$ identical to each other, confirming a common origin, and to two British strains identified in February 2014 (MVs/Brighton. GBR/8.14/ and MVs/Tonbridge.GBR/7.14/, not shown).

\section{Control measures}

Case management and isolation

Upon the suspicion of measles cases, the ship medical team responded rapidly to the event by isolating suspected cases on board. A request for immediate support to the public health offices on shore followed when they realised that isolation of suspected cases and their contacts could not be managed on board. Symptomatic passengers and their close contacts were disembarked and either hospitalised or put in isolation to prevent further transmission.

On February 27, after inspection of the cruise ship by the Civitavecchia Maritime Health Offices, symptomatic crew members and their close contacts were disembarked. Nine crew members were hospitalised at the INMI Spallanzani and 56 were quarantined in 
Flowchart of case management for symptomatic crew members and their close contacts, measles outbreak on cruise ship, Italy, 27 February-1 March 2014

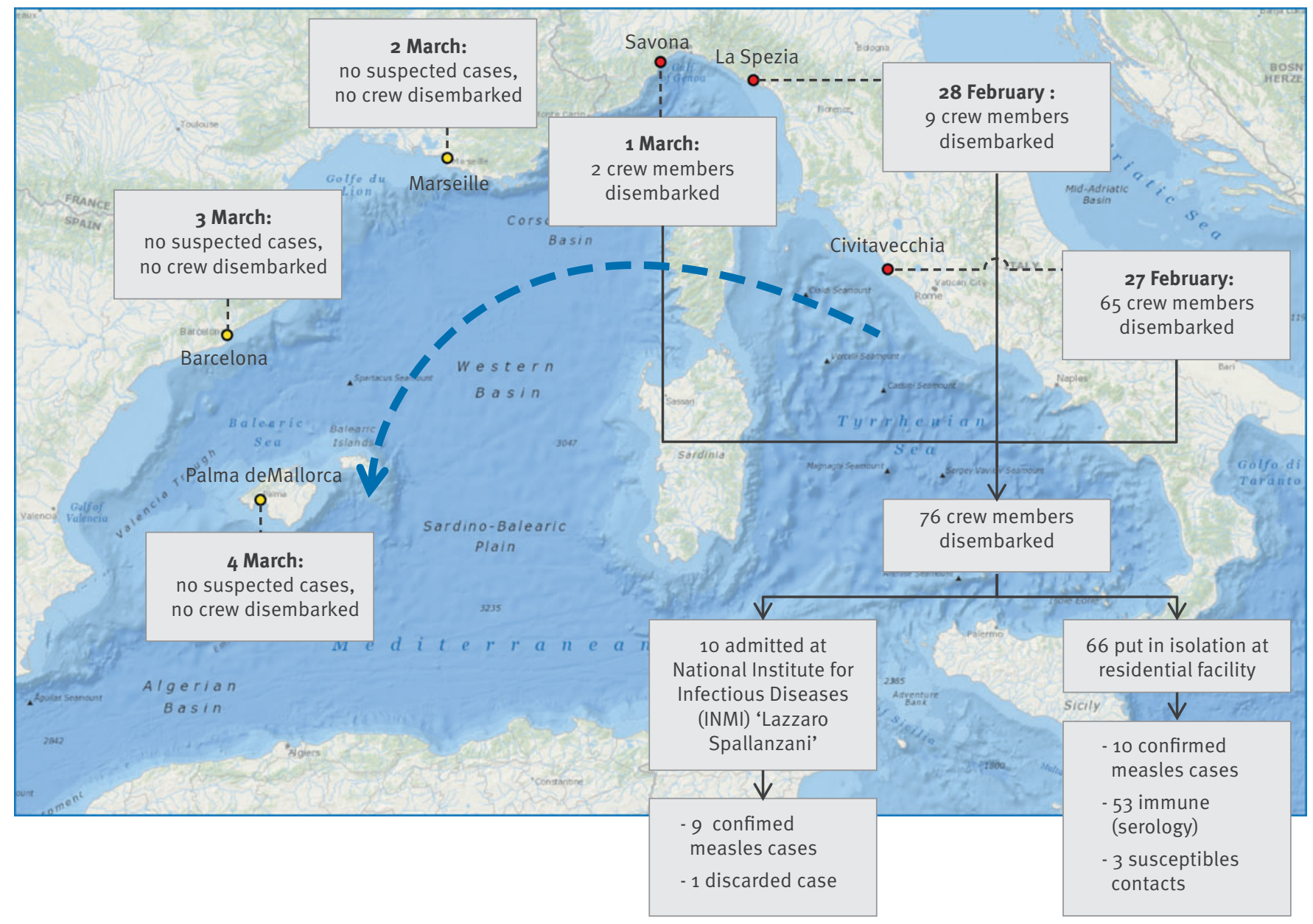

a residential facility $100 \mathrm{~km}$ north of Civitavecchia. Between 28 February and 1 March, after inspections by the Maritime Health Offices in La Spezia and Savona, one additional crew member was hospitalised at the INMI Spallanzani and ten crew members were quarantined in the above mentioned residential facility (nine from La Spezia and two from Savona). Thus $76 \mathrm{crew}$ members were either admitted at the INMI Spallanzani (10, of whom nine were confirmed as measles cases) or quarantined (66, of whom 10 were confirmed as measles cases). Among the 56 crew who were subsequently not diagnosed as measles cases, three were susceptible (anti-measles IgG and IgM negative) and 53 were immune (anti-measles IgG positive and IgM negative). All crew members who had developed symptoms while on board had been isolated prior to disembarking.

The cruise continued according to schedule and was investigated in Marseille on 1 March 2014, Barcelona on 2 March 2014 and Palma de Mallorca on 3 March 2014 by national maritime authorities. No additional measles cases were suspected on board (Figure 2).
Communication and international alerts

Since 28 February, disembarking passengers receive an information leaflet prepared by the cruise line company, in agreement with the Italian $\mathrm{MoH}$, with a recommendation to contact local health services should they develop fever and rash, and to inform the health services that they have been on the cruise ship.

On 27 February, the Italian $\mathrm{MoH}$ communicated an alert through EWRS and the system was also used for communicating patient-related information to International Health Regulations focal points in countries where the exposed passengers originated from. Besides information on the outbreak, countries received lists with names and passport numbers of their citizens disembarked from the cruise. Unfortunately, for some of the EU Member States, in particular those with a high number of national citizens on board, the information provided by the cruise line company was not sufficient to track passengers.

\section{Vaccination on board}

On 27 February, the ship medical team initiated a vaccination campaign with measles-mumps-rubella (MMR) vaccine on board for crew and passengers with no 
evidence of prior immunity. The cruise line company's medical team vaccinated 820 crew members who consented to be vaccinated and eight passengers who voluntarily accepted to be vaccinated. Among crew, 142 recalled previous vaccination and 108 recalled a history of measles. It should be noted that no efforts have been made to confirm serostatus of those who were vaccinated.

Vaccination is now also offered to newly embarked crew members when needed. A median of about 20 new crew members arrive per week on board.

\section{Discussion}

The spread of measles on board of a cruise ship represents a public health challenge $[6,7]$ for several reasons. Firstly, because of the gathering of a large number of people with unknown vaccination status and having close contact in a closed setting, secondly because there is a constant flow of passengers in and out of the ship of passengers, with new susceptible passengers coming on board while potentially infected ones return to their different home countries with opportunity to further spread disease, and thirdly because on-board medical facilities to isolate and care for suspected measles cases are limited.

In the event described, a number of isolation and control measures were implemented on and off board including isolation of cases on board, request for immediate support to the relevant public health authorities at shore when realising that isolation of suspected cases and their contacts could not be managed on board, communication to crew and passengers (both incoming and leaving) and timely vaccination to susceptible crew and passengers. These measures seem to have been successful in controlling the circulation of the virus among the crew and this is indicated by the fact that since 27 February 2014, there have been no cases identified. Strict surveillance is nevertheless maintained among crew as some may have already been incubating the disease when vaccinated.

The limited number of cases reported among passengers to date, only four passengers are known to have developed measles after their stay on board, is likely to be due to underestimation. The average passenger time on board is about seven days which is usually not sufficient for a susceptible exposed patient infected to develop symptoms while still on board (range of 7 to 18 days from exposure to rash onset). However, a patient infected on board may develop symptoms upon return to their home country and infect others. Thus active follow-up of passengers at national and regional level would be desirable. Active contact tracing of passengers was done by some countries in the EU. However, some national authorities faced challenges when trying to contact their citizens due to the limited amount of information on passengers' contact details. Some countries issued press releases and put in place a telephone hotline. In Austria for example, this enabled the identification of one measles case.

Considering the highly contagious nature of measles [8], the cruise line company should continue informing new passengers boarding the ship about the risk of measles transmission on board for at least two incubation periods. To identify possible new cases among passengers after disembarking, the company should inform passengers leaving the ship to contact health services should they develop fever or rash, mentioning the recent cruise.

This outbreak is a further reminder that measles is still circulating in Europe and that actions at all levels are needed to meet the elimination goal. The lessons learnt and recommendations for preventing future occurrence of a measles outbreak on a cruise ship are as follows:

- International guidance for the management of a suspected measles outbreak on a cruise ship is needed and should include recommendations for suspected cases isolation, immediate notification to port authorities, the availability of vaccines on board and the minimal set of information required about passengers to allow for contact tracing.

- Anyone who travels should be reminded upon booking to check their vaccination records and ensure they are protected against measles prior to boarding according to national vaccine recommendations.

It is understood that these recommendations would fall within the wider activities implemented in Europe by health authorities in the frame of the measles elimination plan.

The cost and mobilisation of resources associated with this outbreak are considerable. Actions are now needed to prevent similar events from occurring in the future. Follow-up studies should to evaluate the full extent of this outbreak to learn additional lessons how to avoid the repetition of similar events in the future.

The central task force for the measles outbreak (in addition to the authors) consisted of: S Iannazzo, E Rizzuto (Ministry of Health, DG for Prevention, V Office), V Costanzo (Ministry of Health, DG for Prevention, III Office), S Declich, MC Rota, A Bella, S Salmaso (Istituto Superiore di Sanità, CNESPS), G Rezza (Istituto Superiore di Sanità, DMIPI), N Danielsson, L Pastore Celentano, D Plachouras, E Robesyn (ECDC), N Bevilacqua, L Bordi, F Carletti, E Lalle and E Nicastri (National Institute for Infectious Diseases (INMI) “Lazzaro Spallanzani”).

Acknowledgments

We want to acknowledge the support of Melissa Baggieri, Claudia Fortuna, Antonella Marchi, Paola Bucci and Eleonora Benedetti from the WHO National ReferenceLaboratory for Measles and Rubella in Rome; we are grateful to all staff in local,regional and national health authorities Italy, Austria, Spain and France for investigating and reporting cases. We would also like to thank the Cruise Company for its collaboration with this investigation. We acknowledge the funding support from the Italian Ministry of Health, Ricerca Corrente. 
None declared.

\section{Authors' contributions:}

S Lanini, M R Capobianchi, V Puro, A Filia, M Del Manso, T Karki, L Nicoletti, F Magurano, T Derrough, E Severi, S Bonfigli, FN Lauria, G Ippolito, L Vellucci, M G Pompa, and the other members of the Central task force for the measles outbreak listed above reviewed and approved the manuscript. MG Pompa acted as outbreak coordinator, L Vellucci carried out the environmental investigation; S Lanini, V Puro, M Del Manso, A Filia, T Karki, S Bonfigli, FN Lauria and $G$ Ippolito carried out the epidemiological investigation; MR Capobianchi, F Magurano and L Nicoletti carried out the microbiological investigation and $T$ Derrough, E Severi, S Lanini, A Filia,T Karki, drafted the manuscript and data analysis.

\section{References}

1. European Centre for Disease Prevention and Control (ECDC). Rapid Risk Assessment. Measles on a cruise ship, Mediterranean Sea. Stockholm: ECDC; 2014. [Accessed 12 March2014]. Available from: http://www.ecdc.europa.eu/en/ publications/Publications/rapid-risk-assessment-measlescruise-ship-Mediterranean-5-March-2014.pdf.

2. European Commission. Commission implementing Decision of 8 August 2012 amending Decision 2002/253/EC laying down case definitions for reporting communicable diseases to the Community network under Decision No 2119/98/EC of the European Parliament and of the Council Official Journal of the European Union. Luxembourg: Publications Office of the European Union. Communities. 3.4.2002:L 86/44. Available from: http://eur-lex.europa.eu/LexUriServ/LexUriServ.do?uri= OJ:L:2012:262:0001:0057:EN:PDF

3. Istituto Superiore di Sanità (ISS). Sorveglianza Integrata Morbillo e Rosolia 2013 [Accessed 11 March 2014]. Available from: https://www.iss.it/site/rmi/morbillo/.

4. World Health Organization (WHO). Update of the nomenclature for describing the genetic characteristics of wild-type measles viruses: new genotypes and reference strains. 2003 Jul 4 . Report No.: 0049-8114 (Print) 0049-8114 (Linking) Contract No.: 27. Available from: http://www.who.int/wer/2003/en/ wer7827.pdf

5. Bhuniya S, Maji D, Mandal D, Mondal N. Measles outbreak among the Dukpa tribe of Buxa hills in West Bengal, India: epidemiology and vaccine efficacy. Indian journal of public health. 2013 Oct-Dec;57(4):272-5. PubMed PMID: 24351391. Epub 2013/12/20. eng.

6. From the Centers for Disease Control and Prevention. Rubella among crew members of commercial cruise ships--Florida, 1997. JAMA. 1998;279(5):348, 50.

7. Mitruka K, Felsen CB, Tomianovic D, Inman B, Street K, Yambor P, et al. Measles, rubella, and varicella among the crew of a cruise ship sailing from Florida, United States, 2006. J. Travel Med. 2012;19(4):233-7. http://dx.doi. org/10.1111/j.1708-8305.2012.00620.x

8. Moss WJ, Griffin DE. Measles. Lancet. 2012;379(9811):153-64. http://dx.doi.org/10.1016/S0140-6736(10)62352-5 